\title{
ÁFRICA SUBSAARIANA: ARENA INTERNACIONAL ${ }^{1}$
}

Herbert Schützer ${ }^{2}$

Duarte Luciano Antunes ${ }^{3}$

Resumo: $\mathrm{O}$ atual cenário geopolítico da região subsaariana é pautado por disputas entre as potências centrais e médias na busca das vantagens econômicas, a fim de garantir as riquezas naturais subsaarianas. No atual cenário de disputas geopolíticas em palcos africanos, destacam-se ações de antigos Estados coloniais que visam a consecução de seus próprios interesses, em detrimento das demandas locais. Entre os governos petistas, no Brasil (2003-2016), contudo, esboçou-se um modus operandi diferente do geral. A inserção geopolítica brasileira se deu a nível de colaboração e multilateralidade. Este artigo tem como papel (role) analisar e discutir estas diferentes ações no continente africano, sob a pauta do capitalismo contemporâneo.

Palavras-chave: geopolítica, potências, subsaariana, exploração.

\section{Sub Saharan Africa: international arena}

Abstract: The current geopolitical scenery of the Saharan region is guided by disputes between the central and average power in search of economic advantages to ensure the natural Saharan. With different geopolitical, all seeking the same goals, which do not consider the needs and shortcomings that the region possesses. The repetition of this type of neocolonial exploitation, of the nineteenth century, has in Brazil, as an average power, a differential and it is a geopolitics of government and needs to be incorporated as state policy.

Key-words: geopolitics, power, saharan, exploitation.

1 Uma pequena introdução deste artigo foi publicada em Revista Mundorama (Disponível em: https://www.mundorama.net/?article=africa-subsaariana-a-ultima-fronteira-do-capitalismo-por-herbert-schutzer). Contudo, após ampliação e colaboração, a pesquisa ganhou mais corpo, sendo esta seu produto final com o presente título.

2 Mestre em Geografia Humana FFLCH-USP. E-mail. hschutzer@globomail.com.

3 Mestre em Ciência Política IFCH-UNICAMP. E-mail: duarte.antunes@sme.prefeitura.sp.gov.br. 


\section{INTRODUÇÃO - O “COBIÇADO” CONTINENTE AFRICANO}

Última região a ser integrada ao sistema capitalista, a porção subsaariana do continente africano, está sendo disputada pelas grandes potências mundiais e por potências médias para atender aos mais diferentes interesses. A África subsaariana é o novo e último espaço para o capitalismo alcançar sua universalidade e, consequentemente, estabelecer sua dominação generalizada pelo planeta e de fato chegar ao chamado "fim da história" (FUKUYAMA, 1989). Nesta "nova" arena os principais países do sistema mundial e alguns países de segundo escalão estão colocando em ação suas geopolíticas "soft power", em geral, para atingir as maiores vantagens comparativas possíveis.

Desde o final do século XX e este início do XXI, o panorama subsaariano vem apresentando atrativos na esfera econômica, que atiçam a cobiça das potências mundiais e suas empresas, que acabam contribuindo para a manutenção de um espaço desarticulado e a emergência de Estados decadentes, incapaz de garantir suas premissas socioeconômicas devido à cobiça que promove nas cooptadas classes dominantes locais. Com isso, os países subsaarianos tornam-se presas fáceis dos diversos interesses dispostos nas diversas esferas da vida dos países, que não adotam nenhum critério seletivo nas parcerias propostas e as possibilidades de consolidação das suas estruturas ficam comprometidas. Essa falta de objetivos é, possivelmente, um ranço do colonialismo e suas artificialidades políticas e sociais, como também da Guerra Fria e suas influências nefastas para a formação da jovem região independente.

\section{O CONTINENTE AFRICANO E O CAPITALISMO INTERNACIONAL PÓS-GUERRA FRIA}

Após o fim da Guerra Fria as potências centrais e algumas potências médias, entre elas o Brasil, voltaram seus interesses para o último ${ }^{4}$ espaço mundial ainda não totalmente inserido na dinâmica da globalização - a África Subsaariana com sua diversidade a ser explorada pela lógica neoliberal, “mais mercado, menos Estado". Lógica essa que trás em seu bojo uma gama de práticas que seduzem as classes dominantes e médias de países que procuraram a modernização de suas sociedades, com a ideia de acesso fácil às inovações tecnológicas ao custo de uma flexibilização econômica e política em prol do capital internacional. (CARVALHO, 2002).

Na década de 1990, surgiu uma concepção política abrangente entre as grandes potências

4 Além da Antártica que, por força de suas condições naturais e do Tratado Antártico, continua preservada. 
(como também na ONU) de que o engajamento delas se fazia necessário para garantir um futuro mais promissor para a África Subsaariana. Europeus e norte-americanos lançaram propostas assistencialistas para a região, no intuito de remediar a "tragédia subsaariana" com a canalização de recursos dos países ricos, a fim de modernizar o sistema de produção dos países mais carentes, tendo por base a criação de um sistema eficiente de produção em alguns setores primordiais da economia da região. Porém essas iniciativas, retóricas ou não, foram paulatinamente superadas pelos interesses econômicos imperialistas de um capitalismo globalizante e pelas dificuldades endógenas que a região subsaariana apresentava. (PIMENTAL, 2000) Na intersecção dessas duas variáveis, a região subsaariana tornou a agonizar, em virtude do recrudescimento da violência de diferentes naturezas e das epidemias que se alastraram num meio historicamente carente, provocando um enorme sofrimento da população. Os conflitos anteriores, alimentados pela Guerra Fria, continuaram devido à marginalização estratégica da região no período subsequente e também devido aos paradigmas coloniais que subsistiram.

Passado esse hiato do pós-Guerra Fria, novas geopolíticas nacionais estão materializando interesses distintos, num espaço de grande diversidade e com traços colonialistas que se imbricam à nova realidade do continente, quase cinquenta anos após os processos de independência. As potências usam diferentes práticas de penetração política e econômica e se sobrepõem às políticas locais e aos interesses do principal país da região, a África do Sul. Contudo, todos enfrentam os paradoxos de uma região com uma história que penetra na antiguidade, cujos valores culturais perpassaram pelo colonialismo europeu e por suas consequências e são vivificados na atualidade. Soma-se a isso, por um lado, a presença dos países ocidentais e seus paradigmas, constituindo ideais de legitimação civilizacional, que entram nesse jogo geopolítico de acumulação de poder na porção subsaariana da África. Por outro, as potências orientais legitimadas por diferentes valores, mas atuando com os mesmos objetivos na busca de vantagens comparativas (FIORI, 2007).

A partir dessas premissas, a região em questão aparece na pauta atual dos principais países em condições de ação extraterritorial, pois vêm apresentado números que chamam a atenção e atiçam a cobiça das grandes empresas. Como os das importações, que em 2005 chegaram a 218,9 bilhões de dólares e em 2006 a 293,8 bilhões. O PIB da região passou de 630,8 bilhões em 2005 para 703,5 bilhões de dólares em 2007, justificando o forte interesse que a UE (União Europeia) já vinha demonstrando pela região, quando do concerto produzido pelo Acordo de Cotonu ${ }^{5}$, que

5 O Acordo de Cotonu tem como principais objetivos a redução da pobreza e, a prazo, a sua erradicação e a integração progressiva dos Estados de África, das Caraíbas e do Pacífico (ACP) na economia mundial, em consonância com os 
envolve os Países e Territórios Ultramarinos e os Estados ACP (países da África, das Caraíbas e do Pacífico). Houve ainda estratégias unilaterais mais agressivas por parte de alguns países europeus, na busca das vantagens comparativas e também para não deixar a arena subsaariana a outros interessados. E, devido à morosidade para se produzir uma política no âmbito da comunidade europeia, a Alemanha iniciou em 2007 seu projeto chamado de “Ação África”, que em 2008 vai destinar 20 milhões de euros ao continente, objetivando o desenvolvimento de parcerias em projetos e programas de intercâmbio cultural (AG. LUFTHANSA, 2008). Enquanto isso, a Grã Bretanha se alinha à política de segurança internacional dos Estados Unidos (LIMA, 2008).

O crescimento econômico africano pode facilitar sua inserção no mercado globalizado, devido à atração que vem exercendo sobre os países centrais, os quais vão elaborando novas geopolíticas para o continente, a fim de garantir uma parcela dos rendimentos ofertados pelas novas economias da região. Principalmente as da costa ocidental, na região do Golfo de Guiné.

Os Estados Unidos é outro agente de valor exponencial, possuindo interesses militares e econômicos, uma vez que compreendeu sua dependência em relação às matérias-primas. Principalmente o petróleo, que já contribui com 19\% do importado e deverá chegar a 25\% até 2015, segundo o National Intelligence Council (RODRIGUES, 2003). Contudo será necessário um concerto cooperativo, devido à competição que vai se estabelecer pelo "ouro negro" africano, constituindo-se num dos aspectos geoestratégicos centrais do século XXI. Tanto que os Estados Unidos lançaram o AGOA - African Growth and Opportunity Act - demonstrando a importância estratégica do petróleo e do gás. O peso da região na produção de petróleo nas próximas décadas pode ter um valor econômico representativo, como mostra a tabela 1 a seguir:

Tabela 1 - Exportações de Petróleo da África para outros países

\begin{tabular}{c|c}
\hline País/Região & Exportações Africanas de Petróleo \\
\hline Europa & $36 \%$ \\
\hline Estados Unidos & $32 \%$ \\
\hline China & $9 \%$ \\
\hline
\end{tabular}

Fonte: O Ardina na Geopolítica, 2007. Disponível em: http://janelanaweb.com/crise/geopolitica1.html\#3.

objetivos de desenvolvimento sustentável. 


\section{O CONTINENTE AFRICANO E O DILEMA DA SEGURANÇA INTERNACIONAL PÓS- GUERRA FRIA}

No tocante à questão da segurança internacional, imperativa para conter a movimentação dos grupos terroristas e a expansão islâmica levaram os Estados Unidos a desenvolver um programa de assistência militar através de vários órgãos públicos e privados, como: o Acri (African Crisis Response Initiative); MPRI (Military Professional Resources Inc.), que dão suporte logístico em matéria de segurança preventiva contra o terrorismo (ABRAMOVICI, 2004), mais recentemente a criação de um comando militar para a África (US África Command - Africom) ${ }^{6}$ (ALMEIDA, 2002). Para os Estados Unidos, há um novo jogo geopolítico em marcha na África por parte das grandes potências, e sua política africana vem sendo desenvolvida há algum tempo, conduzindo para a construção do Africom. O. The National Security Strategy of the United States, em 2002, declarou que "combater o terror global" e garantir a segurança energética americana exige que os Estados Unidos aumentem seus compromissos para com a África, e apela para o estabelecimento de coligações que gerem acordos de segurança regional naquele continente. O U.S. European Command, com base em Stuttgart, Alemanha - responsável pelas operações militares americanas na África Subsaariana - aumentou suas atividades na África Ocidental, centrando-se naqueles estados com produção de petróleo substancial e ou reservas no entorno do Golfo da Guiné (que se estende aproximadamente da Costa do Marfim até Angola). O Comando Europeu dos militares americanos desde algum tempo dedica 70 por cento do seu tempo a assuntos africanos; um salto em relação à atividade quase nula até 2003.

Em outubro de 2008 o Africom começou suas operações e gerou certas reações em alguns países subsaarianos, entre eles a Nigéria, que se pronunciou contrária à localização do comando na África Ocidental. A África do Sul se mostrou reticente quanto ao fato dos Estados Unidos estarem dando prioridade ao Golfo de Guiné para a segurança das rotas marítimas do Atlântico Sul. Ainda, outros atores mostraram-se simpáticos a esta questão levantada por atores africanos, como a Grã Bretanha e a França de Sarkozy (2007-2012), com sua visão gaullista e ao mesmo tempo revolucionária. Pretendiam uma ação agressiva e cooperativa na sua tradicional influência na África, que permitiria um reposicionamento geopolítico na direção do centro dos problemas de segurança internacional, mudando grande parte de seu aparelho militar do Gabão, Congo e Dijibuti,

6 Sobre o longo processo histórico da formação e implementação de políticas de segurança internacional estadunidenses para África, ler: ANTUNES, Duarte Luciano. U.S Africa Command: a nova inserção estadunidense na África. 2018. 1 recurso online (147 p.). Dissertação (mestrado) - Universidade Estadual de Campinas, Instituto de Filosofia e Ciências Humanas, Campinas, SP. 
para o Golfo Pérsico. Mesmo assim sem capacidade de intervenção unilateral, que essa potência - a França - e outras já utilizaram em várias oportunidades, garantindo dessa forma um grau de liberdade para as demais nações, velhas e novas potências. De fato, as reações dos países subsaarianos e europeus levaram Washington a dividir o Africom em sub-comandos, para demonstrar outras preocupações do governo americano em relação à região, como afirmou Theresa Whelan, vice-secretário assistente de Defesa para Assuntos Africanos, ao The Zambian Chronicle, em 03 de setembro de 2007:

\footnotetext{
"Algumas pessoas acreditam que criamos o AFRICOM exclusivamente para a luta contra o terrorismo ou para garantir recursos petrolíferos ou desencorajar a China. Isso não é verdade. Embora o extremismo violento é um motivo de preocupação e deve ser abordado, lutar contra esta ameaça não é a principal missão do AFRICOM..." (Disponível em: https:// www.chronicle.co.zw/. Tradução Nossa).
}

Ao contrário de outros comandos, o Africom teria um tratamento especial no Departamento de Estado e Agências de Desenvolvimento Internacional, procurando garantir uma visão mais suave de sua política "soft power" na região, conforme apontou Whelan. Tal política fora reforçada pela criação dos sub-comandos, a fim de que pudessem atender às reivindicações da $\mathrm{SAD}^{7}$ e outros países que defendiam a impossibilidade de um único comando para as forças militares norteamericanas na África, devido às diferenças regionais existentes num grande continente, como afirmara a vice-secretária.

\section{A EMERGÊNCIA DE NOVOS ATORES EM DISPUTA NA ARENA AFRICANA}

Outro ator que vem apresentando significativa importância, a China, com sua tradicional "soft power" win-win, avança sobre a região com seu leque de oportunidades/interesses paralelamente a das potências grandes e médias. De maneira que possam atuar no sentido de alcançar seus objetivos de desenvolvimento. E que levaram o país a canalizar recursos que são investidos nas áreas estratégicas de riquezas naturais (minerais) para garantir seu abastecimento de matérias-primas necessárias à manutenção de sua crescente economia. A presença chinesa na África subsaariana em busca de recursos naturais que garantam seu grande crescimento econômico deu um grande salto a partir de 2005, quando começaram a desembarcar no continente algo em torno 1.000 empresas e centenas de milhares de trabalhadores. (MONTE, 2010) Essa justificativa do forte

7 Siglas em inglês (South African Development Community). 
interesse chinês na região subsaariana e a existência de fontes de energia primária essenciais para seu plano de desenvolvimento está mais aparente quando a Sinopec chinesa suplantou a Shell e a Total nos direitos em certos blocos no "offshore" angolano; são chinesas também as empresas que participam da reconstrução de grandes obras de infraestrutura realizadas em Angola, Moçambique e Guiné-Bissau. Segundo o Conselho de Inteligência Nacional dos Estados Unidos, a China deverá aumentar em 150\% as suas necessidades energéticas (FIORI. 2007), o que faz da região subsaariana uma arena estratégica de sua geopolítica para com isso ter acesso ao mercado da região e, diferente das nações ocidentais, sem nada pretender em troca, ou seja, sem "qualquer tipo de contrapartida politica: sem democracia, nem respeito aos direitos humanos". Somam-se a isso os números chineses na região, que se aproximaram dos 11 bilhões de dólares, em 2006, de IED’s chineses em toda a África, com 800 empresas atuando no continente. Se a China já é uma influência expressiva nestes mercados, com a valorização planejada e no longo prazo do yuan, a tendência é de que haja a amplificação das reservas internacionais e da capacidade de financiamento, assim como da realização de investimentos diretos.

\section{Investimentos Diretos externos na África}

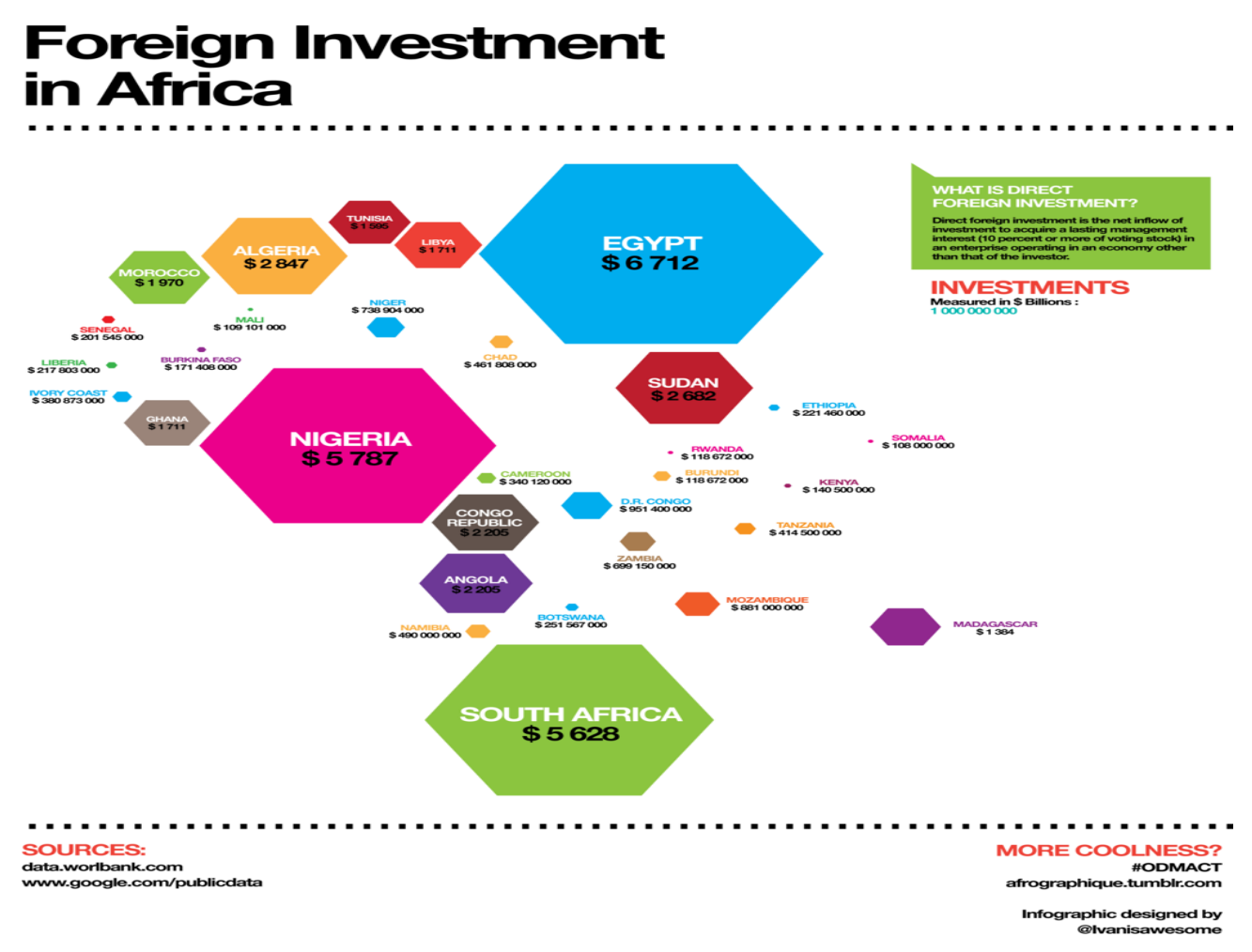

Fonte: World Bank. Disponível em: www.data.worldbank.com. 
$\mathrm{Na}$ realidade os IDEs se concentram mais expressivamente em três países, geograficamente distribuídos, no norte o Egito, no centro a Nigéria e no sul a África do Sul, enquanto o restante do continente recebe individualmente pequenas parcelas do total destinado a região. A África procura um ordenamento político-econômico que garanta a superação do estigma pós-colonial da anomia e assim transmitir confiança a novas parcerias extracontinentais que possuam contribuir para o salto qualitativo pretendido por suas novas lideranças.

$\mathrm{Na}$ África, a presença dos países emergentes, como China, Índia e Brasil, não fora vista como uma nova ação colonizadora, mas como uma oportunidade para recolocar a região em um outro patamar no sistema internacional. Apesar das assimetrias e contradições, a África subsaariana veio construindo uma maior autonomia decisória (SARAIVA, 2008) no âmbito dos organismos regionais e continental É importante o fortalecimento das bases da independência, a superação de inúmeros conflitos, a construção institucional, a conformação de elites com projetos nacionais, instauração das novas democracias, a criação de mecanismos de integração regionais, a obstinada perseguição da estabilização econômica e o combate à pobreza através da dinamização das economias e da União Africana na promoção da paz na região.

Não tardiamente, a outra potência oriental, o Japão, pretende destinar recursos para assistência humanitária no continente, buscando manter sua influência mundial e construir uma nova rede de relações na região, como noticiou o jornal Japan Times. E a Rússia, outro gigante territorial emergente, também possui sua estratégia africana, que pretende uma geopolítica mutuamente vantajosa. "África é uma das direções importantes da política externa russa”, afirmou o Ministro das Relações Exteriores Rússia, Serguei Lavrov (2008), que apoia no âmbito do G-8, a ideia de redução da dívida externa dos países subsaarianos e a necessidade de preparação dos quadros nacionais. Ainda no ano de 2008, o primeiro ministro Mikhail Fradkov visitou Angola, Namíbia e a África do Sul, celebrando importantes acordos de cooperação. No caso angolano, a Rússia procura acordos no setor energético e de minérios; em outros países possui parcerias nos setores financeiro e bancário, madeireiro, pesqueiro, minerador de diamantes, metalomecânico, de equipamentos agrícolas e de transporte, da indústria alimentar, de defesa, segurança e educação. Com isso, busca também fortalecer os laços com suas organizações regionais e sub-regionais, como afirmou o ministro Lavrov em entrevista a Agência Lusa (2008). Dessa forma, a política regional e internacional apresenta uma geopolítica nova, com seus possíveis confrontos de interesses entre grandes potências mundiais, além das potências médias que ali também procuram constituir-se em 
atores desse teatro de operações.

Todas essas ações na África subsaariana demonstram que há uma certa mesquinhez capitalista embutida na ação dos países na região, que buscam satisfazer seus interesses. Destoando desse eixo, o Brasil, no governo de Lula e Dilma (2003-2016), procurou construir uma geopolítica humanista, voltada para colaborar na estrutura espacial produtiva, administrativa e social. Política que se sustentou na relação histórica e cultural com o continente e principalmente com a região subsaariana e, que buscou colaborar, disponibilizado o capital cultural na superação das deficiências para inserir a região no mundo globalizado com seus requisitos elementares, com Estado e sistema produtivo organizado.

Dessa forma, se esperou do continente uma convergência, isto é, os países desenvolvidos entrariam com o aumento de capital financeiro para ajudar África, enquanto os africanos se adaptariam ao neoliberalismo, enquanto o Brasil transferiria as políticas sociais práticas com algum sucesso no país e os conhecimentos para dar incentivos à produção agropecuária.

O presidente Lula procurou reforçar os laços com a região visitando inúmeros países africanos. Em sua primeira viagem à região subsaariana, em novembro de 2003, realizou um périplo por cinco países africanos, Angola, São Tomé e Príncipe, Moçambique, Namíbia e África do Sul, buscando consolidar os laços políticos através do estreitamento das relações do Brasil com a África, que constituía "uma obrigação política, moral e histórica". (BRASIL, 2007) Num cenário internacional indefinido, os desafios da política externa brasileira buscavam encontrar soluções duradouras e equitativas que reflitam o interesse da maioria dos países com quais celebrou atos bilaterais. Procurando realizar relações baseadas na confiança, no interesse mútuo e na solidariedade. O Presidente Lula empreendeu sua segunda viagem à região em julho de 2004, onde visitou São Tomé e Príncipe para participar da V Conferência de Chefes de Estado e de Governo da CPLP, indo posteriormente ao Gabão e a Cabo Verde. Dessa forma, o Brasil passou a ter uma relação diferenciada com vários Estados subsaarianos, Inaugurando 12 novas embaixadas na região e o número de missões diplomáticas africanas em Brasília passou de 16 para 24, em 2003. O Brasil passou a atuar de maneira diferenciada e intensamente na região subsaariana, transcendendo os aspectos comerciais e econômicos, com interesses muito distintos daqueles empreendidos por outros atores na região. Aonde os interesses imediatistas voltados para os ganhos econômicos prevaleciam e prevalecem. Na esfera econômica, o Brasil deixou para as grandes empresas brasileiras a participação na exploração das riquezas minerais e obras de infraestrutura, como as 
obras viárias urbanas e energéticas, contribuindo para a organização e fluidez do espaço dos países subsaarianos. As missões empresariais foram se formando na esteira dessas boas relações desenvolvidas pelo governo. Para facilitar esses investimentos e estimular exportações de bens e serviços, o Brasil ampliou capacidade de crédito para o comércio e os investimentos e criou linhas especiais de financiamento a partir do perdão de dívidas bilaterais. Na área da saúde, por exemplo, no âmbito da CPLP, durante o governo Lula, o Brasil atuou no combate à malária, em Guiné Bissau. Em Angola e Moçambique, o Brasil estabeleceu parcerias para o tratamento da AIDS, além de ter fornecido remédios a preços mais baratos a muitos países africanos. Ademais, a Fiocruz estabeleceu um escritório em Maputo ${ }^{8}$, Moçambique, que cuidou do fornecimento de vacinas, produzida pela fundação (CAMPOS, 2008).

O caráter destoante da política externa brasileira no sentido da autonomia subsaariana, na realidade parece ter um objetivo mais nebuloso do que aparenta. A busca por mercados novos para a economia brasileira faz parte da pauta dessa aproximação e corrobora a ideia da universalização capitalista e seu aparato legal e confirma a ação do país, durante as legendas petistas, com os países que comandam o sistema mundial. O Brasil atuou e ainda atua no sentido de colaborar com as potências mundiais e médias interessadas na região subsaariana usando as opções disponíveis no sistema mundial para países classificados como potências médias, procurando contrabalançar uma ação humanitária na África, com a participação nos fóruns liderados pelos países ricos. O que segundo Andrew Hurrell (2009), leva o Brasil a praticar o "bandwagoning", uma vez que contribui para uma organização do espaço subsaariano, que pode vir a ser mais útil ao sistema capitalista, contudo correndo o risco de latinizar economicamente a região subsaariana.

\section{CONCLUSÃO}

Dessa forma, as perspectivas para a África subsaariana podem ser positivas no sentido da sua organização do espaço e da consolidação do Estado, porém, numa projeção mais de longo prazo, o que se observa é uma continuidade das práticas já desenvolvidas pelas economias mais desenvolvidas em estruturas mais adequadas ao capitalismo. Os anseios subsaarianos parecem não ser considerados na sua diversidade, pois, o 'etnocentrismo' capitalista não leva em conta as questões endógenas das populações locais. O Brasil, em sua atual reformulação política, tendo em

8 Informe da Agência Fiocruz de Notícias acerca do episódio, disponível em: < https://portal.fiocruz.br/noticia/fiocruz-instala-escritorio-em-mocambique $>$.

9 Bandwagoning indica o ato de aliar-se com as potências mundiais e agir livremente no cenário internacional servindo às finalidades de longo prazo a essas potências. $\mathrm{O}$ termo foi originalmente usado pelo cientista político Stephen Van Evera. 
vista a ascensão do bolsonarismo, precisa repensar sua geopolítica subsaariana, para garantir uma atuação não predatória na região e agir no sentido de reforçar as estruturas que garantam uma autonomia para os países da região subsaariana, principalmente, revertendo em benefícios as novas parcerias projetadas durante esta nova direção da política africana que iniciou com o presidente Lula e que pareceu ter continuidade com a presidente Dilma. E assim tentar evitar o processo de espoliação capitalista que vem sendo empreendido pelas potências centrais e médias. Outrossim, que suas escolhas tenham a legitimidade oriunda dos espaços de manifestação interna e externa, na direção da geopolítica humanitária que se propôs no início dessa nova era africana da política externa brasileira e buscar suas aspirações de ator participativo sobre outras bases de legitimidade. Se de fato o país possui o compromisso, como declarou em seu governo o então presidente Lula, que ela se transforme numa política de Estado, o que ainda não parece ter se consolidado com um vai e vem de arranjos e desarranjos, dentro do conturbado momento político pós-lulopetismo, no qual, tem se tornado crime remeter à consciência pública as políticas externas, e mesmo internas, implementadas por esta gestão. A proximidade cultural não deve ficar apenas nos bancos escolares, reafirmando essa proximidade em aulas sobre as eras escravagistas e pós-escravagistas, mas ganhar a consciência da classe política e empresarial num sentido proativo para que as parcerias sejam duradouras e que os benefícios sejam mútuos.

\section{REFERENCIAS BIBLIOGRÁFICAS}

ABRAMOVICI, Pierre. Sob Nova Ocupação. In: Revista Diplô - Brasil. Julho de 2004.

ALMEIDA, Paulo Roberto de. Os Primeiros Anos do Século XXI. São Paulo. Editora Paz e Terra. 2002.

ANTUNES, Duarte Luciano. U.S Africa Command: a nova inserção estadunidense na África. 2018. 1 recurso online (147 p.). Dissertação (mestrado) - Universidade Estadual de Campinas, Instituto de Filosofia e Ciências Humanas, Campinas, SP.

BRASIL, Ministério das Relações Exteriores do. Acordos Brasileiros na África. Departamento de Atos Internacionais. Brasília. www.mre.gov.br/dai/bilaterais -. acesso em: 18 de outubro de 2012.

CAMPOS, Diego Araújo. A África na Política Externa Brasileira. Boletim Mundorama. 08/4/2008. http://mundorama.net. Acesso em 27 de outubro de 2012.

CARVALHO, Leonardo Arquimimo. Geopolítica e Relações Internacionais. Curitiba. Juruá Editora. 2002.

FIOIRI, José Luís. O Poder Global. São Paulo. Editora Boitempo. 2007. 
LIMA, Bernardo Pires de. Sarkozy e o Regresso da França à Política Internacional. Newsletter IDN - Instituto de Defesa Nacional, no. 24. Março / Abril 2008. Portugal. www.idn.gov.pt. Acesso em 23 de junho de 2013.

MONTE, João Bosco. China e África: a política de Pequim para o continente africano. Mundorama DIVULGAÇÃO CIENTÍFICA EM RELAÇÕES INTERNACIONAIS - ISSN 2175-2052. 03/03/2010.

PIMENTEL, José Vicente de Sá. Relações entre o Brasil e a África. Brasília. RBPI vol 43, número 001 p.05-23. 2000.

RODRIGUES, Jorge Nascimento . África - o continente à beira da disputa entre potências. Portugal. Report da frente - O Ardina na Geopolítica. $\mathrm{N}^{\mathrm{o}} 1-4^{\mathrm{o}}$ trimestre de 2007. http://www.janelanaweb.com/crise/geopolitica1.html\#3. Acesso em 10 de junho de 2013.

SARAIVA, José. A África na ordem internacional do século XXI: mudanças epidérmicas ou ensaios de autonomia decisória? In: Revista Brasileira de Política Internacional. Brasília. 51 (1), 2008, pp. 87-104. 